\title{
Pulmonary Manifestations of Juvenile Laryngotracheal Papillomatosis: Case Report and Literature Review
}

\author{
J. Škarda ${ }^{* 1, \S}$, V. Tichá ${ }^{1, \S}$, M. Tichý ${ }^{1}$, M. Perelman ${ }^{2}$ and J. Kopolovic ${ }^{3}$ \\ ${ }^{I}$ Department of Pathology and Laboratory of Molecular Pathology, Medical Faculty, Palacky University, Olomouc, \\ Czech Republic \\ ${ }^{2}$ Department of Pathology, The Chaim Sheba Medical Center and Sackler School of Medicine, Tel Aviv University, \\ Israel \\ ${ }^{3}$ Department of Pathology, Hebrew University and Hadassah Medical School, Jerusalem, Israel
}

\begin{abstract}
In the present report, we report on a rare case of tracheobronchopulmonary spread of childhood recurrent laryngeal papillomatosis without ana association to prior HPV infection, in a 39-year-old female patient.

Recurrent laryngeal papillomatosis (RRLP) is a rare benign disease seen in children and a fewcases are reported in adults. Although RRLP is histologically a benign proliferation of stratified squamous epithelium and is usually limited to the larynx its spread to the tracheobronchial tree occurs in $2 \%$ to $29 \%$ of cases and to the pulmonary parenchyma in less than $7 \%$ of cases.
\end{abstract}

\section{CASE REPORT}

A woman 39 years of age with bilateral focal lesions of the lung. Wedge excision of the lesion in the right lung filled with a purulent secretion.

\section{Macroscopic Appearance}

The lung tissue, $42 \times 30 \times 20 \mathrm{~mm}$ in size had multiple yellowish and graysh lesions of varying size from 2-15 mm with purulent content in the center of the largest lesion.

\section{HISTOLOGICAL FINDINGS}

A-E: In all tisuue sections, the findings were identical, as follows: in lung parenchyma several cavitated lesions lined with sheet-like solid masses of squamous proliferations or flat squamous epithelium could be observed. Similar free epithelial sheets could also be seen in the alveolár spaces without any relationship to the above-mentioned cysts. The epithelium showed dyskeratotic changes with evidence of clear maturation without mitoses or dysplastic changes. The given lesion had oval margins without evidence of invasive growth. Keratin and focal spumoid macrophages could be detected in the alveolar spaces and in the lumen of the lesion (Figs. 1, 2). Due to the peculiarity of the histological picture and vague information from the clinician, we searched the patient database and found that the patient had recurrent laryngeal papillomatosis.

The above histological picture is compatible with pulmonary manifestation of juvenile laryngeotracheal papillomatosis or pulmonary parenchymal papillomatosis.

*Address correspondence to this author at the Department of Pathology and Laboratory of Molecular Pathology, Medical Faculty, Palacky University, Olomouc, Czech Republic; E-mail: jojos@email.cz

${ }^{\S}$ Both authors contributed equally to the study.

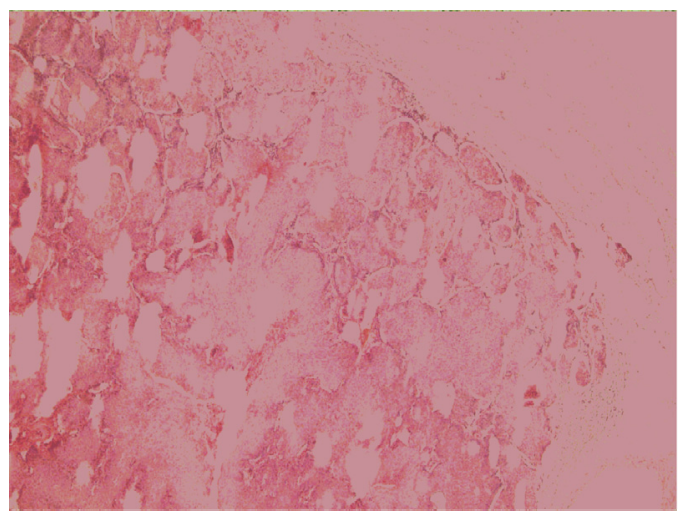

Fig. (1). In lung parenchyma several cavitated lesions lined with sheet-like solid masses of squamous proliferations or flat squamous epithelium could be observed. Similar free epithelial sheets could also be seen in the alveolar spaces without any relationship to the above-mentioned cysts.

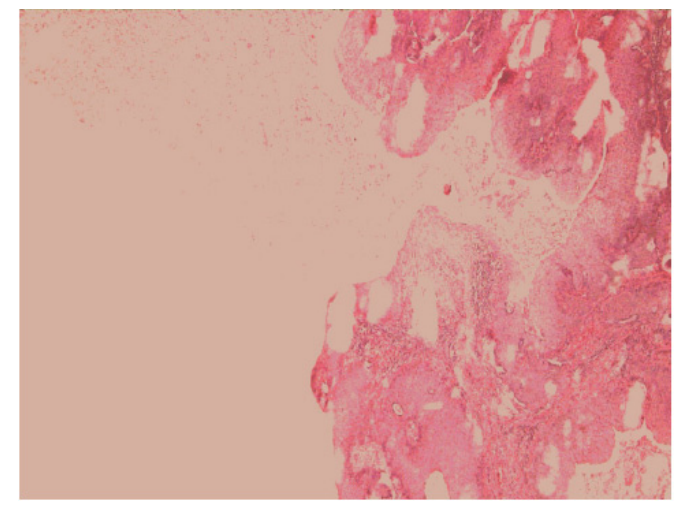

Fig. (2). The epithelium showed dyskeratotic changes with evidence of clear maturation without mitoses or dysplastic changes. The given lesion had oval margins without evidence of invasive growth. Keratin and focal spumoid macrophages could be detected in the alveolar spaces and in the lumen of the lesion 100x HE. 


\section{Histological Findings from the Larynx}

In line with the clinical diagnosis, multiple squamous papillomas with inflammatory changes and proliferation with focal moderate dysplastic changes could be observed. Coilocytes could also be seen. Due to fragmentation, the deep part of the lesion could not be inspected (Fig. 3).

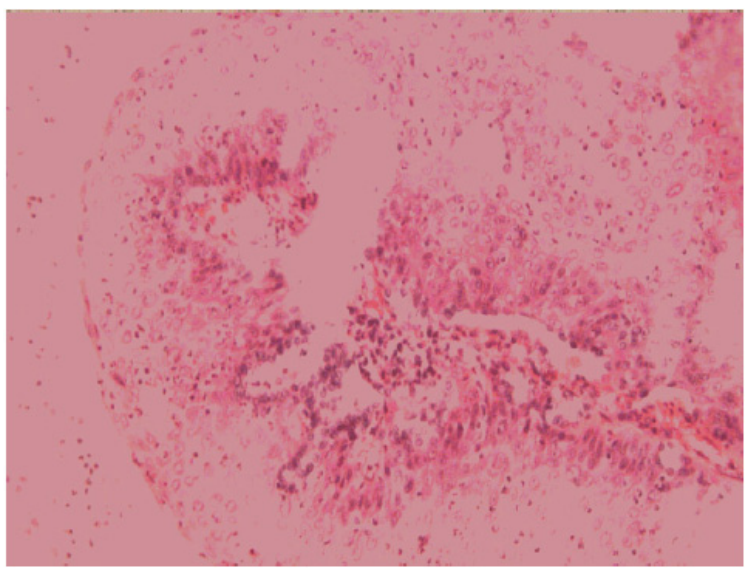

Fig. (3). Histological findings from the larynx: multiple squamous papillomas with inflammatory changes and proliferation with focal moderate dysplastic changes could be observed. Coilocytes could also be seen. 100x HE.

\section{IDENTIFICATION OF THE PRESENCE AND TYPE OF HPV}

Tissue sections from the same paraffin blocks selected for immunohistochemical analysis were used for identification of the presence and type of HPV. The various lesions were separately microdissected using the laser capture technique (PixCell, Arcturus, Mountain View, Calif). An attempt was made to capture as many cells of a given lesion as possible from different foci in each tissue section. This procedure was followed by extraction of DNA and polymerase chain reaction (PCR) amplification using elongated primers that align with corresponding sequences of the L1 region of 23 mucosotropic HPV genotypes.2 These primers can therefore be used to identify pure or mixed infections by 23 mucosotropic HPV genotypes, including HPV-6, -11, -16, $18,-31$, and -33.2 There was no evidence for the presence of another HPV type (HPV-6, -16, -18, -31, -33, or 17 other mucosotropic HPV genotypes that were tested for by the consensus primers) in this lesion. Normal tissue present in the same section as the lesions and used as an internal negative control was negative for HPV in all reactions. In addition, all cases of laryngeal carcinoma associated with RRP were negative for HPV types 16 and 18 using typespecific primers.

\section{DISCUSION}

RLP is a relatively rare disease but is still the most common pediatric neoplasm of the larynx [1,2]. The etiology of the disease is the human papilloma virus (HPV) [3]. The most common types of the virus that have been identified are HPV types 6 and 11 [4]. Other less common presenting types include types 16 and 18; these have been associated more closely with malignant transformation [5, 6]. RLP is classified into juvenile and adult forms. The juvenile form presents as multiple lesions that are unpredictable in their response to treatment and tend to have a high rate of recurrence. In adults, RLP has a male predominance, is most commonly solitary, shows a greater degree of inflammatory reaction, does not tend to spread and recurs less frequently than the juvenile form. The case described is an old adult with recurrences, and distal tracheobronchial and pulmonary spread an uncommon finding in adults. Several explanations for distal spread of RLP have been hypothesized: contiguous extension of papillomas, difuse viral contamination, multicentric origin of papillomas and aerial dissemination of fragments [7].

Tracheostomy and surgical manipulation are thought to induce spread of papillomas to the distal parts of the respiratory tree as may have occurred in the present case given two previous laryngeal operations. Formal tracheostomy should be avoided if at all possible in these patients [8].

The characteristic of RLP in children is a triad of progressive hoarseness, stridor and respiratory distress. In adult patients, hoarseness is the most common symptom as was the case with this patient. When it is extensive RLP may cause respiratory difficulty and even death [4]. There are reports of upper airway obstruction misdiagnosed as asthma. Carroll et al. reported a 21 year old woman who presented with respiratory collapse in the emergency department [9]. Grobbelaar et al. reported three cases with pulmonary hypertension secondary to juvenile RLP [10]. The papilloma appears as an exophytic, branching, pedunculated or sessile mass, single or multiple, most frequently located on the vocal folds, ventricular folds, the subglottis and laryngeal surface of the epiglottis. Histologically, papillomas appear as finger-like projections of stratified squamous epithelium with a fibrovascular core. Basal cell hyperplasia and large vacuolated epithelial cells with a clear cytoplasm (koilocytosis) are typical. When RLP extends into the subglottis or tracheobronchial tree, the epithelium can be squamous or ciliated columnar epithelium [11]. In the present case, we report on tracheobronchopulmonary spread of RRLP in a 39 year old female patient. The biopsy obtained was squamous papilloma, and a biopsy from the left lower lobe papilloma in 2006 showed both squamous epithelium.

The various methods for treating RLP including antibiotics, surgery, radiotherapy, autogenous vaccination, and chemotherapy have generally been unsuccessful. However, some recent studies report that interferon sloha and antiviral agents such as cidofovir show promising results in the treatment of RLP [12-14]. RRLP is known to undergo malignant transformation. Spontaneous malignant degeneration in nonirradiated RLP has been reported in both the laryngotracheal and bronchioalveolar areas, the reported incidence being $2 \%$ to $3 \%$ and occurs within 10 years of diagnosis $[3,7]$. It is thought to be associated with extrinsic factors such as smoking and radiation therapy. However, some cases have been reported in patients without these risk factors [14].

\section{CONCLUSION}

Recurrent laryngeal papillomatosis (RRLP) is a rare benign disease seen in children and a few cases are reported in adults $[1,2]$. Although RRLP is histologically a benign 
proliferation of stratified squamous epithelium and is usually limited to the larynx its spread to the tracheobronchial tree occurs in $2 \%$ to $29 \%$ of cases and pulmonary parenchyma in less than $1 \%$ to $7 \%$ [1]. Adult onset RRLP is usually associated with solitary lesions which do not spread as readily as juvenile forms and recurrence is low after removal $[1,3]$. In the present case, we report on tracheobronchopulmonary spread of RRLP in a 39-year-old female patient without any evidence of associated HPV infection.

\section{REFERENCES}

[1] Abe K, Tanaka Y, Takahashi M, et al. Pulmonary spread of laryngeal papillomatosis: Radiological findings. Radiat Med 2006; 24: 297-301.

[2] Glazer G, Webb WR. Laryngeal papillomatosis with pulmonary spread in a 69-year-old man. Am J Roentgenol 1979; 132: 820-2.

[3] Sidhu TS, Sharma AK, Nishi Sharma, et al. Unusual malignant transformation of juvenile recurrent respiratory papillomatosis. Otolaryngol-Head Neck Surg 2007; 136: 321-3.

[4] Rosai J. Rosai and Ackerman's surgical pathology. $9^{\text {th }}$ ed. Edinburg: Mosby 2004.

[5] Lee JH, Smith RJ. Recurrent respiratory papillomatosis: Pathogenesis to treatment. Curr Opin Otolaryngol Head Neck Surg 2005; 13: 354-9.
[6] Hoasjoe DK, Franklin SW, Aarstad RF, et al. Posterior glottic stenosis mechanism and surgical management. Laryngoscope 1997; 107: 675-9.

[7] Frauenfelder T, Marincek B, Wildermuth S. Pulmonary spread of recurrent respiratory papillomatosis with malignant transformation: CT-findings and airflow simulation. Eur J Radiology Extra 2005; 56: 11-6.

[8] Cole RR, Myer CM 3rd, Cotton RT. Tracheotomy in children with recurrent respiratory papillomatosis. Head Neck 1989; 11: 226-30.

[9] Carroll CD, Saunders NC. Respiratory papillomatosis: a rare cause of collapse in a young adult presenting to the emergency department. Emerg Med J 2002; 19: 362-5.

[10] Grobbelaar I, Seedat RY, Brown S, Claassen AJ. Pulmonary hypertension due to recurrent juvenile laryngeal papillomatosis. Int J Pediatr Otolaryngeol 2005; 69: 1279-82.

[11] Wenig BM, Pilch BZ. Tumors of upper respiratory tract. In Fletcher CDM, Ed. Diagnostic Histopathology of Tumors. London: Churchil Livingstone 2000: pp. 87-169.

[12] Armbruster C, Kreuzer A, Vorbach H, et al. Successful treatment of severe respiratory papillomatosis with intravenous cidofovir and interferon aRLPha-2b. Eur Respir J 2001; 17: 830-1.

[13] Dancey DR, Chamberlain DW, Krajden M, et al. Successful treatment of juvenile laryngeal papillomatosis-related multicystic lung disease with cidofovir: Case report and review of the literature. Chest 2000; 118: 1210-4.

[14] Pontes P, Avenlino M, Pignatari S, Weckx LM. Effect of local application of cidofovir on the control of recurreces in recurrent laryngeal papillomatosis. Otolaryngol Head Neck Surg 2006; 135: 22-7.

(C) Škarda et al.; Licensee Bentham Open.

This is an open access article licensed under the terms of the Creative Commons Attribution Non-Commercial License (http: //creativecommons.org/licenses/by-nc/ 3.0/) which permits unrestricted, non-commercial use, distribution and reproduction in any medium, provided the work is properly cited. 